\title{
Does interactivity require multimedia? The case of SAKI
}

\author{
Michael Horwood
}

Eurotech Training, Oakfield Road, East Wittering, Chichester, West Sussex PO2O BRP

\begin{abstract}
SAKI is a self-adaptive touch-typing tutor with a pedigree dating back to the mid-1950s. Even in its most recent form it eschews the temptation to present itself with the trimmings now commonly associated with microcomputer products. This paper argues that while the absence of such features may be a limiting factor in the commercial success of the program, SAKI is nevertheless a prime example of the way in which a computer can successfully react to and interact with a user, and indeed one which would actually lose educational value if it were to undergo an interface-lift.
\end{abstract}

It should be noted that Eurotech is the official distributor of SAKI

\section{Introduction}

Landa (1976) envisages five fundamental categories of instructional systems:

1. Linear programmes, such as those of programmed learning or page-turning with question-and-answer sessions for verifying understanding before allowing the learner to continue.

2. Intrinsic programmes, where learners are branched to other parts of the programme either as a remedial activity or in order to skip a part where they have already demonstrated understanding. 
3. Extrinsic programmes, which react to a learner's response pattern over a period of time rather than to a single response.

4. Adaptive programmes, which learn from a learner's response pattern and automatically adapt the programme of instruction.

5. Structure-diagnostic programmes, which not only react to the responses made by the student, irrespective of whether they are right or wrong, but also make a diagnosis of the underlying reasons for any incorrect responses.

SAKI (Self-Adaptive Keyboard Instructor) meets the criteria for the adaptive category 4 . It is an intelligent computer-based training program which uses a fully adaptive conversational tutorial mode of instruction, to:

teach 10-finger touch-typing to complete beginners as an automatic reflex-skill

enable competent typists to build on existing skills and improve accuracy, rhythm and speed

- convert two-finger 'peckers' to competent touch-typists

- teach touch-typing to certain categories of handicapped persons.

Using a complex algorithm, it measures the variations in response rates as well as reacting to typing errors (by simple pattern matching) and speed of typing (by using the computer's internal timing device).

It has been developed as a sophisticated MS-DOS version of Gordon Pask's adaptive teaching machine (Pask, 1958a, 1958b, 1960, 1965a, 1982). Its pedigree dates back to the design and testing of such concepts in the late 1950s, and uses Pask's conversational tutorial mode of instruction (Pask, 1980) to learn about individual students. It automatically adapts the instructional process to the student's personal learning style by using error patterns and response rates as controls. In contrast to other typing tutors which use mechanical repetition, SAKI has no pre-set lessons, but uses the controls to concentrate on the areas where the learner is experiencing difficulty.

\section{The history of SAKI}

SAKI was first designed in 1955 at System Research (UK) by Gordon Pask, Elizabeth Pask and Robin McKinnon-Wood (Pask, 1982). One of the first commercial versions was a keyboard trainer for the Hollerith 12 Keyboard, constructed in 1957 for Solartron Electronic Group UK. The machine was used for keypunch training, using one-depression keystrokes for numerical entry and double-depression for alphabetic characters, punctuation, etc. Solartron is said to have sold over 200 machines, each one having been hand-built. They took the form of electromechanical devices, using small film sheets with imprinted rows of letters. Each film was inserted in front of a panel of lights where it remained stationary, cueing the typist by a row of lights illuminated in sequence. The 'exercise block' that was literally screwed into the 
machine was a mate to the film, such that the system knew which letters were being illuminated. Each block contained approximately 128 bytes of memory. There were about 40 pairs of exercises and films covering the instructional process.

The first fully software-based version of SAKI was developed by System Research in the late 1970s. This version was sold as a dedicated machine based on the Research Machines $280 \mathrm{Z}$ microcomputer with the alphanumeric characters on the qwerty keyboard blanked off. The machine was purchased by a handful of major organizations concerned with training large numbers of typists. Among the British organizations which used this version were Honeywell Control Systems, Scheme Management, and Scottish Gas. In the late 1970s the single training station sold for over $£ 2,500$.

In 1981, a new design was developed which achieved greater flexibility and adaptability for the individual student, and easier tailoring to different applications and national languages. In 1986 , yet another new version was written in the C programming language, extra features added, and the software tailored to run under MS-DOS. This version - still the current one has extensive facilities for record keeping, for adjusting the responsiveness of the program, and for customizing the exercise material to individual vocabularies and national languages.

\section{An adaptive approach to learning sensory-motor skills}

In order effectively to examine the public reaction to SAKI, it is first necessary to define the difference between touch-typing and keyboard skills. Keyboard skills are little more than keyboard knowledge: in effect an understanding of the keyboard layout, and purpose and functions of the keys. Touch-typing, on the other hand, is an automatic reflex skill: the user types at a keyboard without mentally processing the individual characters which make up words, and in some cases complete sentences.

Research on typing skills carried out in the course of the development of the original SAKI has been subsequently confirmed (Gentner, 1984). The research has shown that that the skill of an expert typist is due to more than finger-speed alone. Overall typing speed can be measured as a combination of finger speed and lag time between keystrokes, and the primary determinant of the expert's overall typing speed is a consistently short lag between the typing of individual keys. The more expert the typist, the faster the transition from key to key, and as the speed of key transitions increases, typing becomes less sequential. Instead of recognizing and typing one character at a time, the expert can mentally process more than one character simultaneously, without being aware of so doing.

Romiszowski (1986) classifies the various viewpoints on teaching methodology as being either 'prescriptive' or 'democratic'. The prescriptive approach supports individualization on the basis of a comparison between the individual student's approach and some ideal model. Such a comparative diagnosis leads to an individual prescription of learning activities for the student. The democratic (student-centred) approach supports individualization for the student's own sake, the course therefore being adapted to his or her needs. 
There is a certain amount of partisan warfare between these two points of view, on philosophical grounds. For some time, however, an alternative to both of them has been under construction by cyberneticians. Work such as that of Pask (1965b, 1973) suggests that machine-based systems can developed which can learn from the learner, can adapt to the learner's strategy for learning, and can redesign the presentations (on a conversational-tutorial pattern) in ways superior to those achieved by human tutors. Romiszowski concludes that this has certainly been the case with machines such as the SAKI keyboard trainer for high-speed sensory-motor skills.

In the case of SAKI, a complex algorithm measures variations in response rates, and uses those control measures to redesign each line of the typing exercises for the learner around his or her personal learning curve. Where the learner achieves a predetermined level of accuracy and smoothness (this being the consistency of the lag between key depressions), SAKI will remove character(s) from the current exercise and replace them with characters corresponding to the next level of difficulty, accompanied by an appropriate message, such as " $j \mathrm{kl}$; is smooth". Any characters which fall below the acceptable limits of accuracy and smoothness appear more frequently, together with a message such as 'Difficulty with asdf"'. Where the learner's response rates and error patterns fall between the two limits, SAKI repeats the exercise in a slightly different combination without changing the level of difficulty.

Referring to the earlier version of SAKI, with its relative slowness and low level of sophistication, Romiszowski (p. 23) nevertheless writes:

Randomly selected letters appear on screen 1 and the position of each approximate key is 'cued' by the lights that appear on the simulated keyboard on screen 2. [The latest MS-DOS version of SAKI has a screen which is horizontally split into two segments in order to avoid the need for two separate screens.] As practice progresses, the general speed of presentation of data to be typed increases, and the intensity of lights on the simulated keyboard decreases. However all this happens in function of the error pattern of the trainee. He/she gets longer to respond to letters which give difficulty, gets more intense clues and over a longer period of time for these letters and, furthermore, these letters begin to occur at a frequency proportional to their level of difficulty. All this occurs in response to a trainee's individual pattern of errors. He/she gets more practice, more time to respond and more help, adjusted on a continuous, 'on-line' basis by the control algorithm built into -the trainer. This highly adaptive learning environment is extremely efficient, leading typical learners to achieve first-rate typing skills in only a few hours of drill-and-practice.

Romiszowski goes on to discuss how similar adaptive computer-based training devices are now fairly common in military training for developing other psychomotor and perceptual skills such as radar tracking, missile firing and aircraft gunnery. Military budgets, at least during the time of the Cold War, permitted the release of finance to fund research into such sensory-motor training devices. 
Bell (1990) takes the following line on SAKI:

The programme is interesting in that it structures an individual's learning, paying due regard to their initial skills, subsequent errors made and speed of progress. SAKI monitors the learners' performance and adjusts exercises to provide a constant challenge but not one so great as to become demotivating. In doing so it clearly draws upon research into learning (particularly that of Gordon Pask), and into the teaching of typewriting skills.

Rushby (1988) takes a similar positive attitude:

Ironically, one of the oldest and most widely used intelligent CBT packages hides its intelligence so successfully that users are deceived by its apparent simplicity [...]

The skill of classical touch-typing is well-defined, and so it is possible for SAKI to contain an accurate model of the topic that is to be learned. The model of the learner is built and continually adapted by SAKI as the learner works through successive exercises. The program then applies its 'intelligence' to devise new exercises which build on the learner's strengths and tackle the weaknesses.

The result is, at first sight, unexceptional, but after about 20 minutes' use the learner's concentration is intense and the rate at which touch-typing skills are acquired is remarkable.

Rushby's article draws attention to the primary dilemma facing a CBT package as sophisticated as SAKI, and which brings me to the principal point of this paper, impinging as it does on the design of training materials in general and interactive multimedia in particular.

\section{Multimedia for its own sake?}

The question is: given that the presentation of a product is vital to its success, should a designer lower its pedagogical value by changing the the design features in favour of a greater acceptability? For example, does one decide on a multi-colour screen presentation, which may well appeal to an audience unskilled or untrained in the fundamental basis of good instructional design, when the use of colour can actually reduce the effectiveness of the training programme?

The size of the evaluation problem is illustrated by an interesting case. A major international organization specializing in CBT design and assessment (I am unfortunately obliged to withhold the name) carried out an evaluation of SAKI supposedly under controlled conditions. The evaluation team failed to erase the records SAKI was keeping of every move made, thus leaving precise evidence of the assessment procedures which had been followed. The result of the evaluation was that the package was considered unsuitable as a training device for 
delivering touch-typing skills. SAKI's records were later examined. They showed that of the two individuals who carried out the evaluation, one had stayed with the package for less than five minutes, the other for less than two minutes. Neither took a test, nor examined the testing facilities, the customization features or the extensive record-keeping features.

I bring this case to light in order to illustrate the practical problems associated with marketing a high-quality training package where all the effort in the design has been concentrated into the instructional process rather than into a striking or trendy user-interface. The bulk of available touch-typing programs are decorated with multi-coloured screens, flashing "well done, Fred" messages, and other such distractions from the fundamental job of delivering touch-typing as a psychomotor skill. These are the programs, however, which attract and hold the attention of professional reviewers and evaluators.

One thing is certain. Many touch-typing tutors have been designed over the years, some of the simpler ones apparently having been constructed very rapidly and with little real consideration of genuine pedagogical value. The longest surviving is still SAKI, after some 35 years. It does not typify an ultra-modern user interface, but nevertheless provides precisely the kind of automatic adaptivity and interactivity which current computer technology aims to achieve.

In short, multimedia may be about attractive pictures, colourful screen displays and digitized sound, but if in a training package these features detract from the educational value of a program, they can do more harm than good to the reputation and therefore future prospects of interactive applications. Interactivity does not and should not depend on fancy wrapping.

\section{References}

Bell, C., ETTI, 26, 4.

Gentner, D. (1984), Expertise in Typewriting, Centre for Human Interface Processing, University of California, San Diego, April 1984.

Landa, L.N. (1976), Instructional Regulation and Control: Cybernetics, Algorithization and Heuristics in Education, Englewood Cliffs NJ, Educational Technology Publications.

Pask, G. (1958a), 'Electronic keyboard teaching machines', Journal of the National Association for Education and Commerce, July. Reprinted in Glazer, R. and Lumsdaine, A. (eds), Teaching Machines and Programmed Learning, Washington DC, National Education Association, 1, 336-49.

Pask, G. (1958b), 'Research on the design of adaptive teaching systems with a capability for selecting and altering their criteria for adaptation', Reports AF61 (052)-402, Aerospace Medical Research Laboratories. 
Pask, G. (1960), 'The teaching machine as a control mechanism', Transactions of the Society for Instrument Technology, 12, 2 (June).

Pask, G. and Lewis, B.N. (1965a), 'The theory and practice of adaptive teaching systems' in Glazer, R. (ed), Teaching Machines and Programmed Learning, Washington DC, National Education Association, vol. II, Data and Directions, pp. 213-66.

Pask, G. (1965b), The Cybernetics of Human Learning and Performance, London, Hutchinson.

Pask, G. (1980), 'Developments in conversation theory: Part I', International Journal of Man-Machine Studies, 13, 357-411.

Pask, G. (1982), 'SAKI: Twenty-five years of adaptive training into the microprocessor era', International Journal of Man-Machine Studies, 17, 69-74.

Pask, G. and Scott, B.C.E. (1973), 'CASTE: A system for exhibiting learning strategies and regulating uncertainty', International Journal of Man-Machine Studies, 5, 17-52.

Romiszowski, A.J. (1986), Developing Auto-Instructional Materials, London, Kogan Page.

Rushby, N.J. (1988), 'Do we really need intelligent teaching systems?', Personnel Management (March). 